\title{
Impacts of Social Factors and the Health Care Reformation on the Relationships between Physicians and Patients in China
}

\author{
Yushi (Boni) Li \\ Northern Kentucky University \\ Kentucky, USA \\ E-mail: liyu@ nku.edu
}

Received: December 28, 2014

Accepted: February 24, 2015

Published: March 26, 2015

doi:10.5296/iss.v3i1.7322

URL: http://dx.doi.org/10.5296/iss.v3i1.7322

\begin{abstract}
Until recently, China had a free-of-charge health care system in urban areas. Due to a rapid increase in population and economic development, China began health care reformation in the early 1990s. As a result, the relationships between physicians and patients began to change. Recently the relationships have become violent. A number of physicians and hospital staff have been injured, or sometimes even killed by patients and/or their family members. There are many social reasons for such conflicts, such as the level of trust with physicians by the patients and the formation of social stratification and social classes in current China, which did not exist before. This paper analyzes the social factors that impact the relationships between patients and physicians. The analysis emphasizes the limited funds allocated to public health care by the Chinese government and the quality of health services offered by physicians and hospitals. Attention is also given to other social issues, such as the impact of private health care and the difficulties of obtaining medical services by the majority of the Chinese people, after the health care reformation took place.
\end{abstract}

Keywords: conflict relationships, patients trust in physicians, private and public hospitals, the reformation of the Chinese health care system, social stratification, and the formation of social classes 


\section{Introduction}

China's economy has developed rapidly over the past twenty years and many social changes have simultaneously taken place including numerous unpredictable challenges. For example, the relationships between physicians and patients have become cursory. Among the nationally well-known heinous cases which commonly happen in the Chinese public hospitals, quite a few physicians have either been killed, or severely injured by patients and/or their family members. Some physicians were even forced to attend the funeral of a patient, whose life could not be saved, even when it was later proven that it was a natural death and not the fault of the physicians ( $\mathrm{Li} \& \mathrm{Hu}, 2008 ; \mathrm{Ni}, 2012$ ). In the past decade, from 2000 to 2013, there were more than 150 nationally recognized severe conflict cases between physicians and patients. These violent cases have resulted in the deaths of more than 30 people (Liu \& Liu, 2013). In 2011, there were more than 10 brutal killing cases of physicians and/or hospital employees. During the first three months of 2012, three cases of such violence were reported. In 2013, one incident led to the killing of a physician and left two others wounded. Di (2014) points out that the violent attacks on Chinese physicians showed an upward trend at the beginning of 2014. For example, in February of 2014 within two days of each other but in separate hospitals one physician was killed and one was seriously injured. According to LaFraniere (2012), Chinese hospitals are an arena that shows patients' discontent. These attacks highlight the current social issues within professional health care services.

In order to comprehend the issues of trust and health care in China, it is important to first understand the current reformation of the health care system, along with private and public hospitals in China.

\section{The Medical Care Reformation}

After the People's Republic of China was founded in 1949, the Chinese government started to provide a free-of-charge medical care system in urban areas in the early 1950s. At that time, the majority of the Chinese people about $80 \%$ lived in rural areas, where they were not provided the same free-of-charge system. Only urban residents, who worked for the government or government owned enterprises, received this free health care system. A majority of the urban residents at that time worked for the government due to Socialist characteristics. In the 1950s, the number of people who used this free health care system was limited, due to the size of the urban population and because the average age of the recipients in the health system was relatively young. By the end of the 1980's, the free health care system covered about 150 million urban people (Chen, 1994). Many retired urban dwellers continued to receive the free-of-charge health care services. The current elderly population aged 65 and over reached 110 million people in 2010 (Morris, 2012), which was $8.1 \%$ of the total population. In January 2013, the population in China was 1.35 billion (World Population Review, 2013). The youngest people, under 15 years, consisted of 16\% (The Henry J. Kaiser Family Foundation, 2012). The average life expectancy increased from 45 years in 1949 to 73.5 years over a timespan of about sixty years $(\mathrm{Li}, 2011)$. The higher average life expectancy indicates that the standard of health in China has improved. The rapid increase in the number of elderly and longer life expectancy also resulted in unprecedented impacts on the free 


\section{Macrothink}

Issues in Social Science

ISSN 2329-521X

2015, Vol. 3, No. 1

health care system. These findings have resulted in a growing concern over available funds for free health care services provided by the government.

In the past, a patient in the hospital only needed to pay a low registration fee to visit with the doctor. This was not considered a co-pay, but rather it was necessary for regis tration purposes. In the 1980 s, the registration fee was $¥ 0.15$ (Chinese currency), which is equivalent to a few cents in the U.S. today, If using college graduates as an example, when graduating from school, they received $¥ 56$, which was equivalent to $\$ 9-10$ as their monthly income. Urban people who utilized this free health care system also received free prescriptions. Currently, for doctor visits the registration fee ranges from $\$ 1.00$ to $\$ 50$, depending on the credentials of the doctor. If an ordinary Chinese person were to see a doctor or a specialist frequently, then a $\$ 50$ registration could be expensive. Salaries in China today vary for different jobs and work experience. For example, a college graduate can receive $¥ 2,000$ to $¥ 5,000$ or more as monthly income, depending on their job, which is about $\$ 330$ to a little more than $\$ 800$. The registration fee is not the real issue that Chinese people are facing; rather it is the cost of expenses for new co-pays and prescription drugs.

\section{The Recent Establishment of Private Hospitals}

In 2009, the Chinese government started to practice new health care strategies, which has been a continuous program since the medical care reformation that started in 1994. The new strategies permitted the usage of national health insurance for medical services to be done in private clinics or hospitals. However, private hospitals are expensive, even with health insurance, and the majority of the patients are still using public hospitals. The strategy of establishing more private hospitals does not seem to either alleviate the pressures on national public hospitals, or reduce the burden for physicians. This is because the ratio of physicians in China is only 14.6 per 10,000 people (The Henry J. Kaiser Family Foundation, 2012). Due to the huge amount of patients in public hospitals on a daily basis, the relationships between physicians and patients have become cursory.

In contrast to physicians and other specialists in private clinics in the western world, patients in China highly depend on public hospitals, where most physicians, surgeons, and other specialists are working. Since China is currently a socialist society, the public hospitals are government owned. In recent decades, the government began to allow the establishment of private hospitals (Table 1). Since they are new to the medical society and due to the limited number of doctors, these hospitals have limitations on what services they can provide. Even though most people understand that the quality of services is better in private hospitals, the majority of patients have to go to public hospitals for their health issues. 
Table 1 Number of public and private hospitals in China*

\begin{tabular}{llll}
\hline Year & 1949 & 1990 & 2010 \\
\hline No. of public hospitals & 2,600 & 14,377 & 20,918 \\
No. of private hospitals & $--*$ & - - $^{*}$ & 7,068 \\
\hline
\end{tabular}

* The above numbers of hospitals do not include local community health centers, emergency centers, and rural village health clinics.

* -- data is not available.

The data is from the Yearbook of Chinese Health Statistics, the Ministry of Health, PRC. 2011. http:/www.moh. gov.cn/htmlfiles/zw gkzt/ptjnj/year2011/index2011.html

\section{Public Hospitals}

Chinese public hospitals are officially divided into three categories (Table 2): Generally speaking, all of the national hospitals are in the category of 'Level A', which are mainly located in large cities and province capitals. Many nationally renowned physicians are working within the most advanced public medical facilities. Although their annual salaries are much lower than physicians in the western world, and lower than physicians in Chinese private hospitals, most physicians choose to work in public hospitals, where they are able to experience an array of medical cases and have more promotion opportunities with a better chance at becoming well known. When patients suffer serious health problems, they would like to go to 'Level A' hospitals. The next two levels, 'B and C' are city and local, which are most likely considered for minor health needs. The current situations in National level hospitals have made it difficult to obtain registration to see a physician, meaning, either patients or their family members have to get up early to stand in a long line to be registered, or spend up to $¥ 300$ (\$50) for registration fees to see an expert.

Table 2 Beds/per ten thousand people and levels of public hospitals in China*

\begin{tabular}{llll}
\hline Year & 1949 & 1990 & 2010 \\
\hline Hospital beds/10,000 people & 8.0 & 186.89 & 338.76 \\
No. of level A hospitals & $--*$ & $--*$ & 1,284 \\
No. of level B hospitals & $--*$ & $--*$ & 6,472 \\
No. of level C hospitals & $--*$ & $--*$ & 5,271 \\
\hline
\end{tabular}

* The above levels of hospitals and beds do not include local community health centers, emergency centers, and rural village health clinics.

*-- data is not available.

The data is from the Yearbook of Chinese Health Statistics, the Ministry of Health, PRC.2011. http://www.moh.gov.cn/htmlfiles/zwgk zt/ptjnj/year2011/index2011.html 


\section{Issues of Health Care Services}

The current reformation of the Chinese medical system has some major issues that need to be examined. These include three dimensions: The first dimension is limited funds in public hospitals. After the reformation of the medical care system, public hospitals have had to be financially independent due to the limited resources from the government. Public hospitals have to take care of the daily costs, purchasing new medical facilities, and the salaries of physicians and hospital staff. In order to obtain the highest profit, hospitals have increased the expenses of pharmaceuticals and screenings, which greatly increase the burden for patients. For example, in order to receive enough funds for a hospital visit, patients are required to purchase prescription drugs, in the hospital-owned pharmacy after seeing a doctor there. This has become a greater portion of the profit a public hospital can obtain.

The second dimension includes some negative social influences on medical services, which are: 1) incompatibility between the social rewards that physicians receive and their responsibilities, 2) survival of hospitals by selling facility examinations and prescription drugs, and 3) a lack of medical resources that lead to inducement cases. First, due to limited funds, doctors in public medical services work longer hours with more psychological pressure from their job and do not receive adequate salaries. According to a survey in the city of Guangzhou, the average income of a physician in 'Level A' hospitals was over $\$ 6,700$ in

2012. However, the actual income reached $¥ 175,000$ after subsidies, which is equivalent to

$\$ 28,850$ (Zhong, 2014). The average income of a physician was higher than the national average family income in 2012, which was \$2,100 (Wong, 2013). However, physicians' income is not compatible to their longer hours, responsibilities, and number of patients they work with every day. This is considered one of the root causes of a physician's impatient attitude in the work place. For example, there is less discussion or explanation to the patients and their families regarding their health. The procedure the physicians used to diagnose their patients is just a few minutes in length. Then, the physicians will decide to prescribe further tests, such as a CT scan, or they will write a prescription for drugs. This is the second negative social influence on medical services. According to Zhong (2014), the survival of Chinese physicians and hospitals highly depends on selling prescription drugs and using medical facilities. Furthermore, if one patient visits different physicians within different hospitals, with the same health issue, they must redo all the tests because no hospital accepts other hospitals' test results.

Third, in public hospitals, when patients are unable to obtain limited resources, such as hospital beds, or necessary surgery/surgeons, patients and their families have to resort to unethical means, such as slipping money to the surgeons or relevant physicians. These costs could range from $\$ 100$ to $\$ 1,000$ or more. This has almost become a tradition. Both physicians and the patients' families understand this even though the government and public hospitals post regulations on receiving money from patients. However, most patients are warned about the possible negative results of not giving money to the physicians by their relatives and friends. At this point, the money that patients have slipped to physicians seems to only buy peace of mind. After receiving the money, patients and their families expect their 
health issues to be resolved. If the health issues cannot be resolved, they find fault with the physicians, and claim that the doctors did not try their best. If the patient's life cannot be saved during the process of treatment or surgery, the families are sad and angry. Patients/families believe that if the surgeons/physicians accept the money, they should be successful, no matter what kind of health conditions the patient is already in. If the patient's life cannot be saved, conflicts arise and lead to violent behavior.

The third dimension is the unequal social positions of physicians and patients. In hospitals, physicians and patients do not have equal social positions regarding the control of medical knowledge and resources. Physicians make decisions on the process of treatment for patients, this leaves patients essentially powerless. Due to their health issues and difficulties obtaining services, such as being granted an opportunity to see a doctor, patients have always had high expectations of their physicians, especially those who are considered experts in the nationwide hospitals, where a majority of conflicts/injury/killing occur. As discussed above, due to the overload of the work along with the crowds of patients waiting outside of their offices every day, physicians have little or no time to discuss health issues with individual patients. In addition, some of the physicians keep a deliberate distance from the ir patients because they do not want to offer more information in order to avoid liability. The physicians' behavior may dictate patients' attitude regarding their confidence in finding a cure for their health problems.

\section{The Negative Effects on the Levels of Trust and Relations hips between Physicians and Patients}

In the process of dealing with medical violation incidents, an important factor in the above conflict, has not been given enough recognition - the relationships between physicians and patients in the current Chinese medical system. According to Siebzehmer et al. (2008), with rapid social change, the relationships between physicians and patients have become one of a supply and demand. Therefore, the relationships between physicians and patients are facing great challenges. To establish a good relationship, building trust between physicians and patients has become one of the central features (Pearson \& Raeke, 2000; Thorn et al., 2002). Thorn et al. (2002) point out that patients with low trust prior to the visit, were more likely to report a low level of satisfaction, and felt that a requested service was not provided, making it less likely that they would follow their physician's advice. According to Lewis and Weigert (1985), trust includes two important dimensions: one is emotional, and the other is cognitive. For instance, an emotional measurement can be defined as having a strong feeling or reaction to a situation or person. The cognitive aspect involves psychological processes, such as understanding information and attitudes or decision making. Therefore, effective communication between physicians and patients becomes essential (Simpson, et al., 1991; Leng, 2013). A physician commonly sees 50-60 patients before noon in Chinese hospitals (Zhong, 2014), which leaves almost no time for discussion about the cause of the health issues, how it influences the patient's daily life, or what should be done to improve the health condition. In other words, there is not any communication and the process of listening, explaining, or considering the concerns of the patients is absent. In turn, patients show dissatisfaction and low levels of trust toward their physicians, because their behavior does not 
meet the expectations of the patients and their families. According to Ludwig and Burke (2014), patients consider physicians their medical saviors. It is understandable that there are barriers to effective physician-patient communication. However, without effective communication, the level of trust diminishes, which in turn results in patients receiving less information than needed in order to make good treatment decisions. Good communication skills include active listening to patients' concerns and providing enough information, detailed explanation, and feedback from physicians (Simpson, et al., 1991). According to Leng (2013), dissatisfaction by patients indicates poor trust and trust has traditionally been analyzed as an important factor of effective physician and patient relationships (Rowe \& Calnan, 2006). The violent cases within the Chinese medical facility indicate that relationships between physicians and patients have major issues, and that trust levels are quite low. A quality doctor-patient relationship is essential, especially for vulnerable patients, who are experiencing a heightened reliance on physician's competence, skills, good listening and communication (Goold \& Lipkin, 1999). Slipping money to the physicians indicates that distrust has been forged between patients/families and the physicians/hospitals. Due to the high demands placed on physicians and lack of doctor-patient communication, many patients and their families are willing to pay extra money for the possibility of special treatment, and longer consultations. More than a decade ago, people never had to slip money to surgeons/physicians in order to have a special treatment or a peace of mind. Patients relied on physicians for medical care built on mutual trust. The question we are trying to answer is: What factors have impacted Chinese medical services in the past decade, turning hospitals into a conflict arena between patients/families and physicians?

\section{Other Important Social Change Factors on Medical Care Services}

The recent increase of social inequality has directly affected the quality of medical care services. With uneven economic development in China since the 1990s, some Chinese people have become much wealthier than others. The rich have more choices when needing medical care services. They are able to go to private hospitals, or are able to pay higher registration fees to see experts in public hospitals. They can also pay more to receive an individual hospital room, while most patients have to share one room with multiple people, even in an ICU room. As discussed earlier, China used to have a free-of-charge health care system and everyone who used the system in urban areas had equal opportunities for hospital services. However, this is not the case in current China. Due to the recent formation of social classes, the poor cannot compete with the rich for different social opportunities, especially for life chances or medical treatments. The majority of people have to wait for a very long time before receiving a hospital bed, or they may have to stand in a long line for many hours before being registered to see a physician. They have to bear the lack of quality services and the lack of communication with physicians. Furthermore, the money that socially disadvantaged people give to a physician could be their total monthly income, or could be borrowed from others. However, medical costs are nothing for those who are rich and the rich only account for a small percentage of the Chinese people. Recent formation of social stratification has helped people realize that life is even harder than before, especially when facing their health problems. 


\section{MInstitute ${ }_{\text {Mnk }}^{\text {Macrothink }}$}

Issues in Social Science ISSN 2329-521X 2015, Vol. 3, No. 1

According to the study done by the Ministry of Civil Affairs of the People's Republic of China (Ministry of Civil Affairs of the People's Republic of China, 2007), data shows that there is an unequal distribution of wealth in today's Chinese society. Most of the wealth is controlled by a small group of people in the country, which has resulted in tension and conflict. Even though the middle class is in the developmental process, this class, in current China, only makes up a relatively small percentage, compared with the un-wealthy majority (Balfour, 2011).

As discussed earlier, physicians' salaries are relatively low because they work for public hospitals. Due to the unequal distribution of wealth, the longer working hours and the lower income have resulted in complaints. With rapid economic growth in China, most people tend to evaluate their success by their financial status. Therefore, most physicians would evaluate that what they contributed to the society is much more than what they receive from the society. In turn, this has resulted in development of negative attitudes, regarding their jobs. In addition, the work they are doing is high pressure. Their salaries do not reflect the risks they have to face every day. Another issue, as discussed earlier, the Chinese government does not allocate enough funds to medical facilities, especially the public hospitals. This has forced each hospital to seek its own financial means of survival. Basically, hospitals will encourage physicians to prescribe patients more expensive drugs and unnecessary tests. A famous quote in China for this phenomenon states: "the survival and growth of the hospital fully depends on selling of pharmaceuticals and tests". The focus on financial gains in hospitals has become an important aspect of the conflict between patients and physicians, it should be the focal point for the current and future medical system reformation.

The violent behavior by patients/families reflects the issues surrounding the health care system in China. Medical health care, in any society, should be a social benefit provided by the government to its people. If profits are overly considered and involved in decision making, it will result in dissatisfaction, distrust, and complaints not only by patients/families, but also by health service staff and physicians. The violent relationships between physicians and patients are only a social phenomenon that represents a much deeper dissatisfaction towards the medical care system and the present implementation of social stratification. If the root causes are not analyzed and thus new strategies created, it will be difficult to transform these hospitals into peaceful environments where physicians can provide quality care for their patients.

\section{References}

Balfour, F. (2011), China's Millionaires Leap Past 1 Million on Growth, Savings. [Online] Available: http://www.bloomberg.com/news/2011-05-31/china-s-millionaires-jump-past-one -million-on-sa vings- growth.html

Chen, K. W. (1994). The Issues of Medical Care System with the Economic Reformation in China. Modern China Studies, 3, 42.

Di, Y. F. (2014). Violent attacks on Chinese physicians have shown an upward trend. [Online] Available: http//cn.nytimes.com/china/20140222/c22doctor/ 


\section{Macrothink}

Issues in Social Science ISSN 2329-521X 2015, Vol. 3, No. 1

Goold, S. D., \& Lipkin, M. (1999). The Doctor-Patient Relationship-Challenges, Opportunities, and Strategies. Journal of General Internal Medicine. 14, S26-S33. [Online] Available: http//dx.doi.org/10.1046/j.1525-1497.1999.00267.x

LaFraniere, S. (2010). Chinese Hospitals Are Battlegrounds of Discontent. The New York Times. [Online] Available: http://www.nytimes.com/2010/08/12/world/asia/12hospital.html

Leng, S. (2013). How can doctors and patients regain trust in each other? Kevinmd.com. [Online] Available: http://www.kevinmd.com/blog/2013/08/doctors-patients-regain-trust.html

Lewis, J. D., \& Weigert, A. (1985). Trust as a social reality. Social Forces, 63(4), 967-985. Li, B., \& Hu, L. (2008). Trust is the Core of the Doctor-Patient Relationship: From the Perspective of Traditional Chinese Medical Ethics Philosophy and Medicine, 1, Vol. 96. China: Bioethics, Trust, and The Challenge Of The Market, Part II, pp. 39-44. Li, Z. Y. (Ed.) (2011). China's average life expectancy reaches 73.5 years. People's Daily Online. [Online] Available: http://english.peopledaily.com.cn/90882/7616444.html

Liu, J. \& Liu, N. X. (2013). The history of the Chinese medical violent cases South Weekend. [Online] Available: http://www.infzm.com/content/95720

Ludwig, M., \& Burke, W. (2014). Physician-Patient Relationship. [Online] Available: https:/depts. washington.edu/bioethx/topics/physpt.html

Ministry of Civil Affairs of the People's Republic of China. (2007). The tendency of the changes in the social stratification in current Chinese society. Policy Research Center. [Online] Available: http://zyzx.mca.gov.cn/article/mjzl/lq/200712/20071200009109.shtml

Morris, D. (2012). China's aging population threatens its manufacturing might. CNBC. [Online] Available: http://www.cnbc.com/id/49498720

Ni, T. (2012). Hospital violence sign of doctor-patient strife. Shanghai Daily. [Online] Available: http $/ /$ www.china.org.cn/opinion/2012-05/07/content_25321732.htm

Pearson, S., \& Raeke, L. (2000).Patients' Trust in Physicians: Many Theories, Few Measures, and Little Data. Journal of General International Medicine, 15(7), 509-513. [Online] Available: http//www.ncbi.nlm.nih.gov/pmc/articles/PMC1495476/

Rowe, R., \& Calnan, M. (2006). Trust relations in health care-the new agenda. Eur J Public Healt, 16(1), 4-6. [Online] Available: http://eurpub.oxfordjournals.org/content/16/1/4.full

Siebzehner, M., Balik, C., \& Matalon, A. (2008). Doctor-patient relationship in the context of a changing society (Article in Hebrew). Harefuah, 147(12), 1010-1015.

Simpson, M., Buckman, R., Stewart, M., Maguire, P., Lipkin, M., Novack,D., \& Till, J. (1991). Doctor-patient communication: the Toronto consensus statement. BMJ VOLUME, 303, 1385-1387. [Online] Available: http://www.ncbi.nlm.nih.gov/pmc/articles/PMC1671610 /pdf/bmj00155-0047.pdf

The Henry J. Kaiser Family Foundation. (2012). Physicians (Per 10,000 people). Global Health Facts. [Online] Available: http:/kff.org/global-indicator/physicians/ 


\section{Macrothink}

Issues in Social Science ISSN 2329-521X 2015, Vol. 3, No. 1

The Henry J. Kaiser Family Foundation. (2012). Population under age 15 (Percentage). Global Health Facts. [Online] Available: http://kff.org/global-indicator/population-under-age $-15 /$

The Ministry of Health, PRC. (2011). 2011 Yearbook of Chinese Health Statistics. [Online] Available: http//www.moh.gov.cn/htmlfiles/zwgkzt/ptjnj/year2011/index2011.html

Thom, D., Richard L, Kravitza, R., Bellb, R., Krupatc, E., \& Azarid, R. (2002). Patient trust in the physician: relationship to patient requests. Family Practice, 19(5), 476-483. [Online] Available: http//dx.doi.org/10.1093/fampra/19.5.476

Wong, E. (2013). Survey in China shows a wide gap in income. [Online] Available: http://ww w.nytimes.com/2013/07/20/world/asia/survey-in-china-shows-wide-income-gap.ht $\mathrm{ml}$ ?_r=0

World Population Review. (2013). Population of China 2013. [Online] Available: http://worldpopulationreview.com/population-of-china/

Zhong, N. S. (2014). The survival of the Chinese physicians depends on the sales of drugs and medical facility examinations. [Online] Available: http://news.sina.com.cn/c/2014-03-05 /165129630935.shtml 